\title{
Classification of synoptic patterns in the western Arctic associated with extreme events at Barrow, Alaska, USA
}

\author{
Elizabeth N. Cassano ${ }^{1, *}$, Amanda H. Lynch ${ }^{2}$, John J. Cassano ${ }^{1,3}$, Melinda R. Koslow ${ }^{1}$ \\ ${ }^{1}$ Cooperative Institute for Research in Environmental Sciences, UCB 216, University of Colorado, Boulder, Colorado 80309, USA \\ ${ }^{2}$ Geography and Environmental Science, PO Box 11A, Monash University, Victoria 3800, Melbourne, Australia \\ ${ }^{3}$ Program in Atmospheric and Oceanic Sciences, UCB 311, University of Colorado, Boulder, Colorado 80309, USA
}

\begin{abstract}
The coastal geography of Barrow, Alaska, makes the city vulnerable to weather events that cause flooding and erosion. This study uses the self-organizing map (SOM) algorithm, an unsupervised learning process that codifies large, multivariate datasets onto a 2-dimensional array, or map, to study large-scale circulation patterns associated with temperature and high wind extremes at Barrow. The analysis first uses the SOM algorithm to produce an automated 55 yr synoptic climatology of daily sea level pressure patterns for the western Arctic for August to November, when the area is potentially ice free. The results are in agreement with previous Arctic climatologies, showing the Aleutian Low to be dominant in southern Alaska, and high pressure prevalent over the Beaufort and Chukchi Seas. The SOM algorithm is then used to study circulation patterns associated with temperature and high wind extremes at Barrow. These results show that high winds are associated with patterns containing a strong pressure gradient between the Aleutian Low and the Beaufort and Chukchi Seas and also with patterns that contain a low pressure system to the north of Barrow. High (low) air temperature extreme anomalies are associated with patterns that produce strong, southerly (northerly) air flow at Barrow. This study demonstrates the utility of using SOMs to investigate the relationship between local weather conditions and large-scale patterns. This approach can be applied to future global climate model (GCM) simulations to investigate the impact of changes in large-scale circulation patterns to local extreme events.
\end{abstract}

KEY WORDS: Synoptic climatology · Self-organizing maps · SOM · Large-scale circulation · Extreme events

Resale or republication not permitted without written consent of the publisher

\section{INTRODUCTION}

The city of Barrow $\left(71^{\circ} 18^{\prime} \mathrm{N}, 156^{\circ} 47^{\prime} \mathrm{W}\right)$ is located at the northernmost point of the USA on the shore of the Arctic Ocean (Fig. 1), and has an average elevation of $<10 \mathrm{~m}$ above sea level (the elevation of the meteorological station is $10.7 \mathrm{~m}$, one of the higher points in the town). Its exposed location, combined with the increasing instability of the coastline due to thawing permafrost (Lynch et al. 2004) makes Barrow vulnerable to wind damage, erosion, and flooding associated with extreme weather events. In addition, the town has expanded and modernized substantially in recent decades, increasing the potential costs due to damage from extreme events (Lynch et al. 2004).
The majority of the permanent residents of Barrow and the North Slope of Alaska are Inupiat Eskimos, and at least half of the adult Inupiat Eskimos participate in a subsistence lifestyle (NSB 1999). Subsistence activities remain an important part of the culture and life of the Inupiat Eskimo people. However, this lifestyle is vulnerable to changes in climate, which have been observed and are expected to continue in the Arctic (Serreze et al. 2000, IPCC 2001, ACIA 2004, Hinzman et al. 2005). It has been postulated that if the changes occurring now extend into the future, extreme weather events may occur more often, and possibly in more rapid succession, making recovery from a single extreme event more difficult (Wigley 1985). Hence, extreme weather events are of great concern to Barrow residents. 


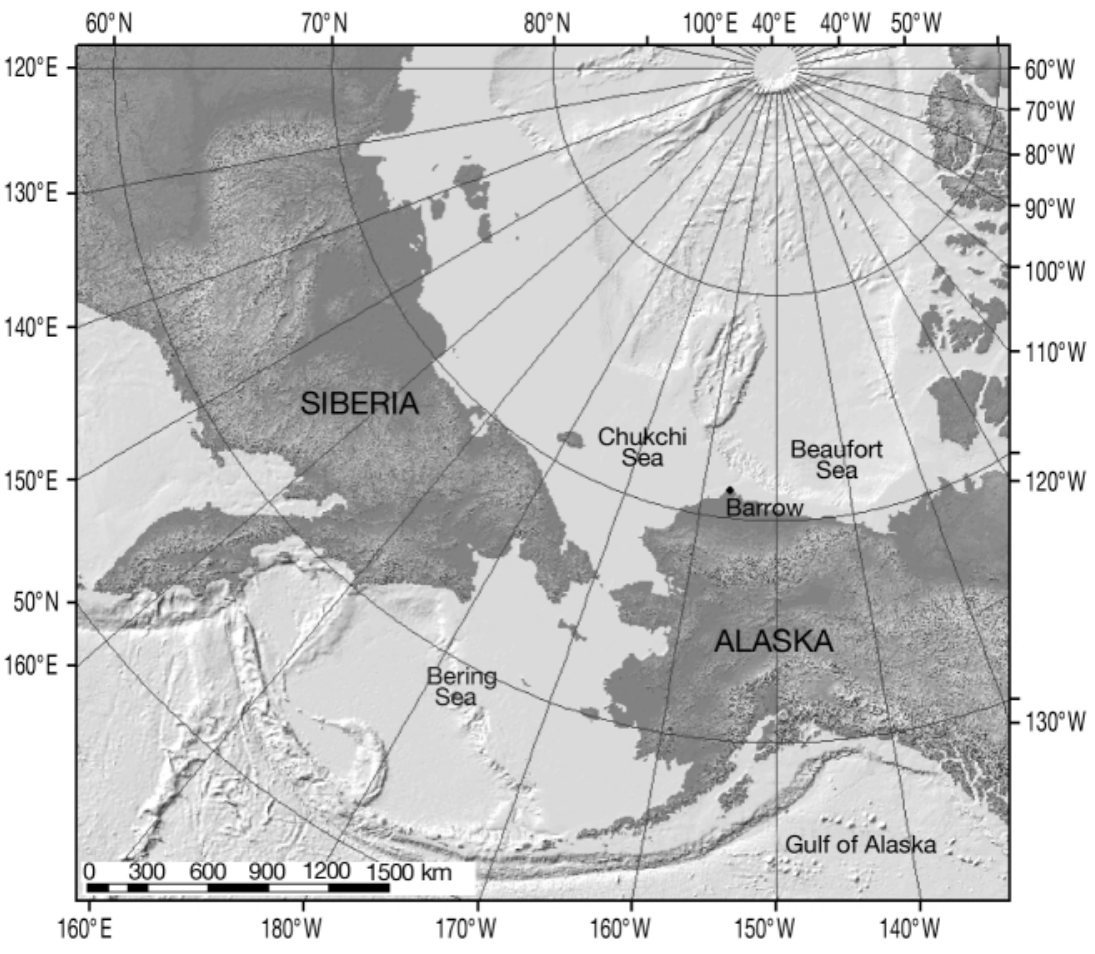

Fig. 1. Location of study area

niques such as those applied by Lamb (1950) or more sophisticated data reduction methods such as correlation or cluster techniques (Holt 1999, Solman \& Menéndez 2003, Esteban et al. 2005). The assumption inherent in all of these classification methods is that the weather conditions associated with each type are consistent, with distinct boundaries between categories (Barry \& Perry 2001).

Another method of classification which is relatively new to climate research is the self-organizing map (SOM) (Kohonen 2001). This method employs a neural network algorithm that uses an unsupervised learning process to discover patterns in data. The final product of this technique is a 2-dimensional array, or map, of classes that are representative of the probability density function of the input data. The classes are placed in the input data space so that they span the continuum of data, and more classes are located in areas of higher data density. The arrangement of the final distribution

Barrow is located on the west shore of Point Barrow. Atmospheric and sea ice conditions that can lead to storm surge via Ekman transport and wave setup are caused by synoptic weather patterns that produce high, sustained westerly winds coupled with large fetch (open water or low sea ice concentration in the direction of the wind). In general, these weather patterns consist of a synoptic or mesoscale low pressure system to the north of Barrow and/or a high pressure system to the south. However, while several such events that were extreme enough to cause significant damage have occurred (e.g. Lynch et al. 2003), these are not typical patterns in this area. From earlier Arctic climatologies (Keegan 1958, Reed \& Kunkel 1960, Moritz 1979, LeDrew 1983, 1985) to more current ones (Serreze et al. 1993, Brümmer et al. 2000, McCabe et al. 2001, Lynch et al. 2003), the Beaufort/Chukchi sector of the Arctic (Fig. 1) does not exhibit much cyclonic activity, and in fact the Beaufort and Chukchi Seas are an area of frequent anticyclones. These anticyclones, coupled with low pressure in southern Alaska, result in prevailing ENE winds of about $5 \mathrm{~m} \mathrm{~s}^{-1}$ at Barrow (Moritz 1979).

The basic aim of synoptic climatology is to relate local or regional climate to the large-scale atmospheric circulation (Barry \& Perry 1973). This requires classifying atmospheric circulation types and then relating a local variable (e.g. temperature, wind) to these circulation types. There are many different methods by which this classification is done, e.g. manual, subjective techof the classes places those with similar characteristics close together in the map, dissimilar ones further apart, with gradual transitional classes in between. The SOM is the end result of this procedure, manifested as an organized array of classes. For our application, the input data to the SOM algorithm are time series of atmospheric state variables and the classes that are identified represent archetypical atmospheric states. This method provides an effective way of objectively classifying and visualizing the synoptic states which span the range of conditions represented in the atmospheric data.

The relatively coarse resolution of global climate model (GCM) simulations and global re-analyses makes it difficult to resolve local extreme events at a specific location, although these extreme events are often of greatest concern to residents at that location. However, the relationships between the large-scale circulation and local extreme events can be determined using the SOM in conjunction with station data. Once these relationships are determined, they can be used for other applications such as local community planning purposes. For example, if a large-scale circulation type associated with previous extreme local events is forecast, this gives the community time to determine the responses, if any, that will be taken to prepare the community for a possible extreme event. This relationship can also be applied to GCM simulations of future climate to evaluate possible changes in the frequency of large-scale circulation patterns con- 
ducive to extreme local events. Cassano et al. (in press) and Lynch et al. (in press) apply this technique to identify changes in the frequency of occurrence of synoptic patterns in polar regions predicted by an ensemble of GCMs for 21st century climate change simulations conducted in support of the Intergovernmental Panel on Climate Change (IPCC) Fourth Assessment Report (AR4). This study demonstrates the utility of using the SOM method to establish the relationships between large-scale circulation and local extreme events in Barrow.

The focus of the present study is to use the SOM to relate circulation patterns in the western Arctic to local conditions at Barrow. For this application, the SOM algorithm was used to codify daily synoptic sea level pressure (SLP) patterns for the western Arctic based on re-analysis data. Then further analysis focused on extreme events by using the SOM to identify synoptic situations associated with extreme temperature and winds at Barrow for the months of August to November, when the area is potentially ice-free. Section 2 describes the SOM algorithm in more detail and provides a description of the data used in this study. Section 3 discusses the general classification of SLP patterns for the western Arctic using the SOM. Section 4 discusses results of the classification of patterns associated with extremes events at Barrow, and Section 5 is a summary of results and a discussion of future work.

\section{METHODS AND DATA}

\subsection{Description of the SOM}

SOMs have been used across a wide range of disciplines (Kaski et al. 1998, Oja et al. 2003), but are relatively new to climate research, although their use for climate applications is increasing rapidly. Hewitson \& Crane (2002) used the technique to classify synoptic patterns over the east coast of the United States, and to relate these patterns to local daily precipitation. Cavazos $(1999,2000)$ used SOMs to classify patterns representative of extreme wintertime precipitation, and to identify large-scale circulation anomalies associated with these events. Ambroise et al. (2000) used SOMs for cloud classification and Malmgren \& Winter (1999) used SOMs to classify climate zones in Puerto Rico. Crane \& Hewitson (2003) used SOMs to analyze precipitation data from the mid-Atlantic and northeastern USA while Reusch et al. (2005) applied the SOM methodology to aid in interpreting Antarctic ice core data.

Formally, the SOM may be described as a non-linear mapping of high-dimensional input data onto the elements of a regular low-dimensional array (Kohonen 2001). This array, called a map, is a 2-dimensional matrix of reference vectors, or nodes, that are representative of the probability density function of the input data. The nodes are of the same dimension as the input data vectors, with the nth value of the node corresponding to the $\mathrm{nth}$ value of the input vectors (Hewitson \& Crane 2002). The SOM seeks to place a user-selected number of these nodes in a distribution of input data. The classes will be placed in the data space such that each class is representative of the surrounding data. The number of nodes chosen will depend on the intended application and the size of the data space spanned by the input data. In addition, the number of nodes selected dictates how much intranode spread will be represented by the classes. More nodes will produce a broader range of patterns with more gradual differences between them, while fewer nodes will result in both larger intra-node and internode spread, though the same broad patterns will be revealed in each case.

A strength of the SOM is that it is an unsupervised learning process, i.e. there are no assumptions made as to the final clusters of the data. The final map evolves, or learns, from the input data. The classes become characteristic of the input data by being 'trained' by the input data. First, the SOM nodes are randomly initialized in the input data space. An input data vector is presented to the SOM and is compared to all of the nodes in the initial map. The node that it is closest to (as a measure of Euclidian distance) becomes the winning node. This node is then modified to reduce the difference with the input vector based on a learning rate parameter in the algorithm. The learning rate controls how fast this process occurs (a small value leads to a slow and smooth learning process and a high value to a fast but unstable learning process (Gutiérrez et al. 2005). In addition to the modification of the winning node, the neighboring nodes are nudged towards the input data vector in a distance weighted fashion. The number of adjacent nodes that are modified is specified by the radius of the training area, and the amount of adjustment varies in inverse proportion to the distance from the initially identified node and in proportion to the learning rate parameter. Thus each input sample contributes to the characterization of more than one node. As the process continues, the number of neighboring nodes surrounding the winning node updated through each iteration decreases linearly to 1 (so by the end of the iterations only the winning node is updated), and the amount that the winning node is nudged towards the input sample decreases to zero throughout the iterative process.

In the final product, the nodes have become 'ordered', i.e. nodes that are close together in the map have similar patterns due to the process of each input data sample training the winning node and those sur- 
rounding it. For the case of using the SOM to classify SLP patterns, patterns dominated by high pressure will be located on one side of the map and patterns dominated by low pressure will be on the opposite side, with transitional states between the two (e.g. see Fig. 2).

Michaelides et al. (2001) used SOMs to classify long term variability of the rainfall regime of Cyprus. They also compared classification using the SOM versus that produced using traditional cluster analysis. They found the SOM classification categorized the classes more uniformly, while the traditional cluster analysis grouped most of the data into a few distinctive classes with the remaining data as outliers. For applications such as the study of infrequent events (e.g. extreme events), this attribute of traditional cluster analysis techniques represents a disadvantage. An advantage of using the SOM for synoptic classification versus other classification methods is that the SOM treats the data (atmospheric states) as a continuum. Atmospheric modes are continuous, non-linear and span different space and time scales. These characteristics are not well represented by correlation-based synoptic climatological methods, such as principal component analysis (Barry \& Perry 2001). The SOM does not try to make the data fit a predetermined distribution or model. The SOM places more nodes in areas of higher data density and fewer nodes where there are fewer data. This allows the SOM to represent more subtle variations between classes where the data allow it (Hewitson \& Crane 2002). Thus, the SOM is an effective tool for objectively organizing and finding patterns in data. It is an effective way to visualize relationships between the different classes (or in the case of SLP classifications, different synoptic states) and is applicable across a wide range of climate research studies. A theoretical description of the SOM algorithm is found in Kohonen (2001) and a comprehensive description of its application to climate studies can be found in Hewitson \& Crane (2002).

Sammon mapping is used to represent how each node in the original data space is related to each other node. The Sammon mapping algorithm fits the data points (nodes) onto a 2-dimensional space, so that the Euclidian distances between the nodes approximate the corresponding distances in the original data space (Sammon 1969). This is done to illustrate how the nodes are related to each other, in that some patterns are more similar to adjacent patterns than others.

\subsection{Data}

The time period of the analysis presented is 1950-2004 for the months of August through November, for a total of $6710 \mathrm{~d}$ (input data samples) studied.
These months were chosen to encompass the period of the year that is potentially ice free at Barrow and therefore poses the greatest risk of storm surge/flooding and coastal erosion. The region of study (Fig. 1) covers Alaska, part of Siberia, and the Beaufort and Chukchi Seas. This study area was chosen to capture the scope of synoptic patterns that affect Barrow.

Daily SLP data from the National Center for Environmental Prediction/National Center for Atmospheric Research (NCEP/NCAR) Reanalysis project (Kalnay et al. 1996) were used to capture larger, longer-lived cyclones and thus focus on those cyclones that are more likely to cause damaging winds and floods at coastal locales. This latitude-longitude dataset was reprojected to the National Meteorological Center $47 \times$ 51 octagonal grid, so that each data point is approximately equidistant to the surrounding points, with a nominal grid spacing of $190.5 \mathrm{~km}$. Cullather \& Lynch (2003) compared NCEP/NCAR Reanalysis SLP data with drifting camp measurements in the Arctic Ocean and found high correlations, although significant seasonal discrepancies with a cold season bias were evident. Further, while they were able to qualitatively reproduce their results using the Arctic Ocean Buoy Program (AOBP) data set, an optimal interpolation of Arctic buoy data and the drifting camp data, they concluded that shortcomings remain which require that error bounds of up to $2 \mathrm{hPa}$ be taken into account.

Local wind and temperature data were obtained from the National Weather Service (NWS) station in Barrow. The data used for the analysis were daily wind speed, wind direction, and temperature, and were checked for quality and consistency before use.

\section{SYNOPTIC PATTERNS FOR THE WESTERN ARCTIC}

A general classification of daily SLP patterns for the western Arctic was created using a SOM of $5 \times 4$ nodes (20 classes), to represent the variety of patterns associated with extreme events, yet keep the map simple enough to visualize easily. A variety of map sizes and parameters (learning rate, radius, and number of iterations) were tested, and created a final map with a small quantization error, but in all cases these optimal maps were nearly identical. We conclude that the final map is quite robust and not particularly sensitive to the input parameters for the SOM algorithm. Once the training was completed, the input data were again presented to the SOM algorithm so that individual daily SLP fields could be associated with individual nodes on the map.

Fig. 2 shows the SOM general classification of mean daily SLP patterns for the western Arctic. The Aleutian 

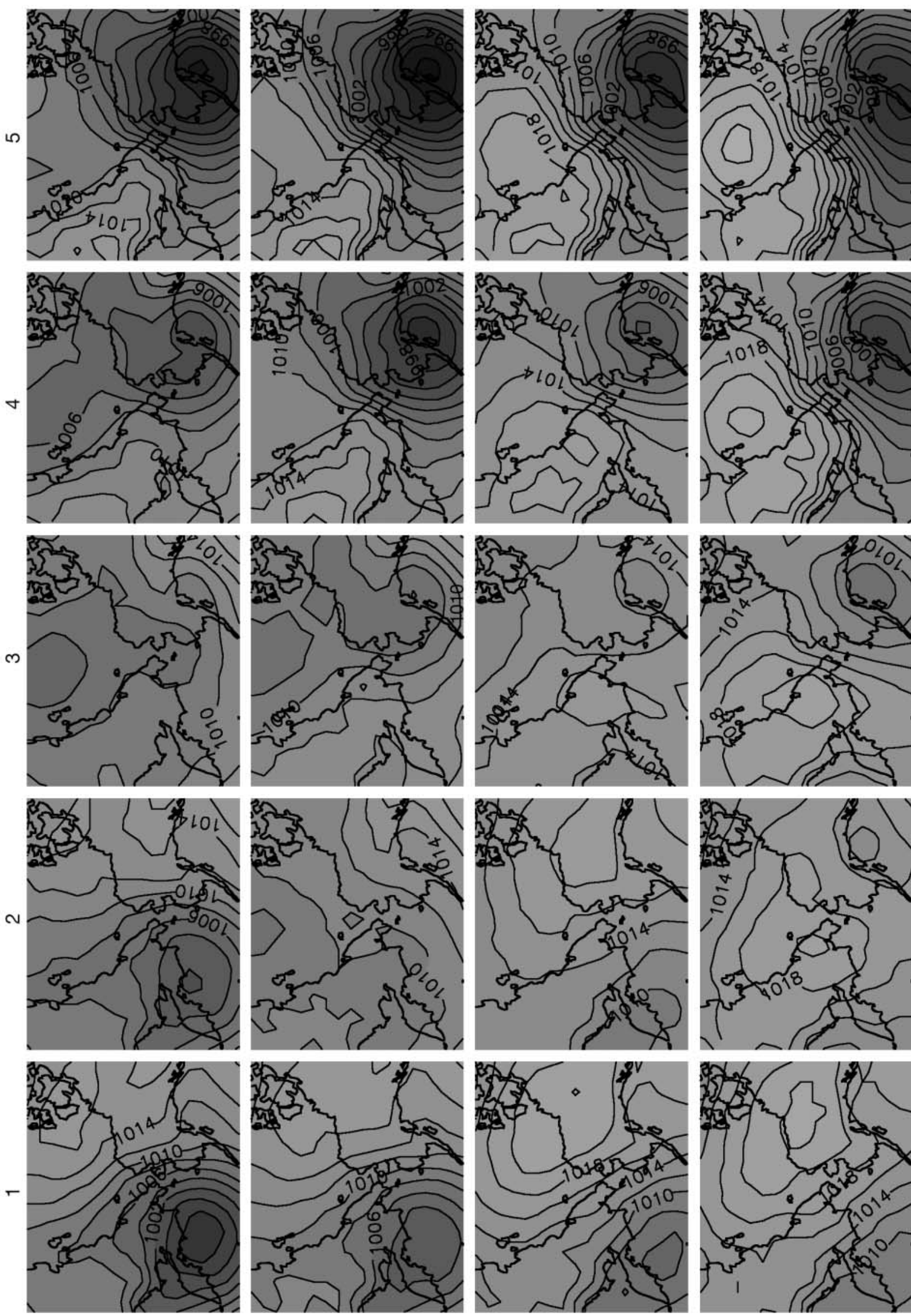

$-$
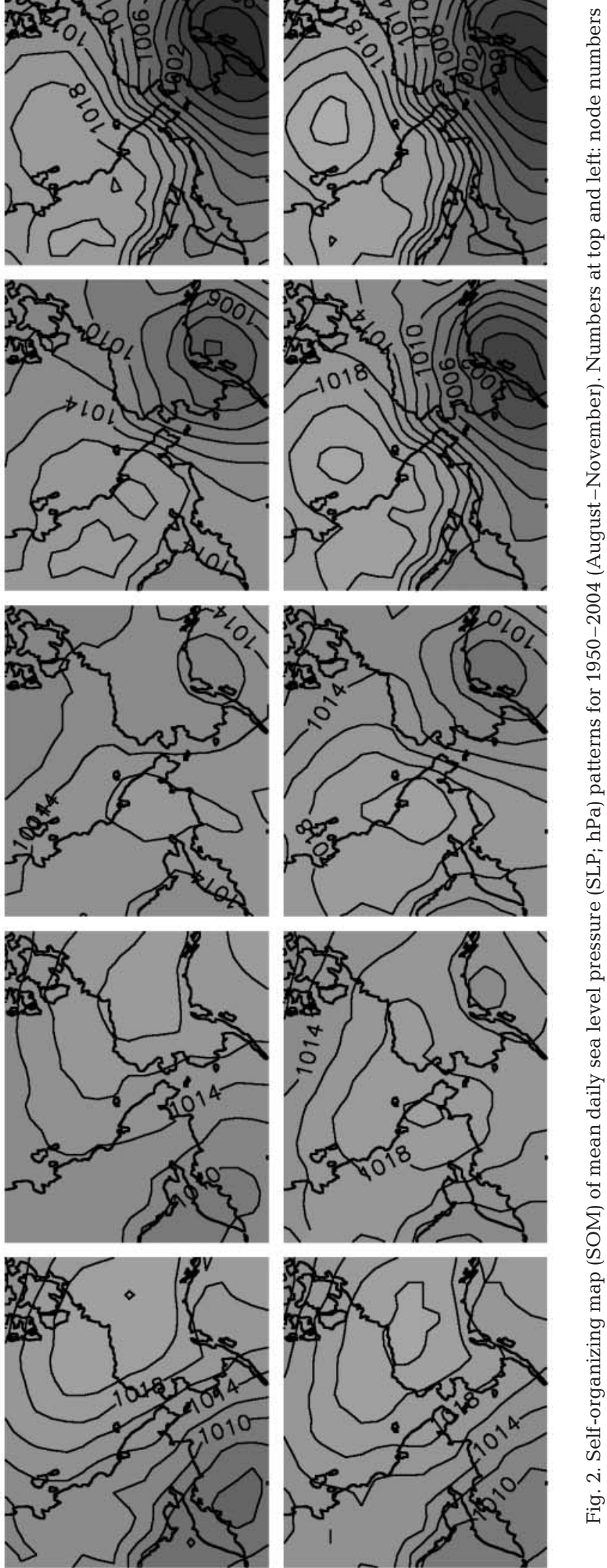

$m$

$\checkmark$ 
Low, which is dominant in this region (Overland \& Hiester 1980), is a prominent feature of many of the nodes, present in patterns along the right (the rightmost 2 columns) and upper left (nodes 1,$1 ; 1,2 ; 2,1$ ) portions of the map. In general higher pressure is dominant around Barrow with Beaufort and Chukchi cyclones being relatively infrequent. These results are in agreement with previous Arctic climatologies (Keegan 1958, Reed \& Kunkel 1960, LeDrew 1983, 1985, Serreze et al. 1993, Lynch et al. 2003) and thus demonstrate the ability of the SOM methodology to create useful and meaningful synoptic climatologies. Fig. 2 also demonstrates a strength of the SOM, in that similar synoptic circulation patterns are clustered together on the map. This is an important attribute of the SOM methodology, since it allows analysis on a node by node basis and also on a map area by map area basis, as appropriate. Fig. 3 shows the Sammon mapping of the SOM shown in Fig. 2. Each point represents one of the nodes of the SOM (in the same orientation as in Fig. 2), and the lines connecting the points are representative of the Euclidian distance between the nodes. This shows that patterns in the upper left (nodes 1,1; 2,1 ) and lower right corner (nodes 4,$4 ; 5,4$ ) of the map are more similar to adjacent nodes, while nodes across the center of the SOM (between the second and third rows) are more dissimilar. However, on balance, the nodes are rather evenly spaced.

The daily SLP data used to train the SOM can then be individually identified with their winning SOM node. The frequency of days (shown as a percent of the total days studied) that map to each SOM node is shown in Table 1. The highest frequencies are associated with patterns dominated by the Aleutian Low. Almost $18 \%$ of the total days map to patterns associated with a westward shift of the Aleutian Low (upper

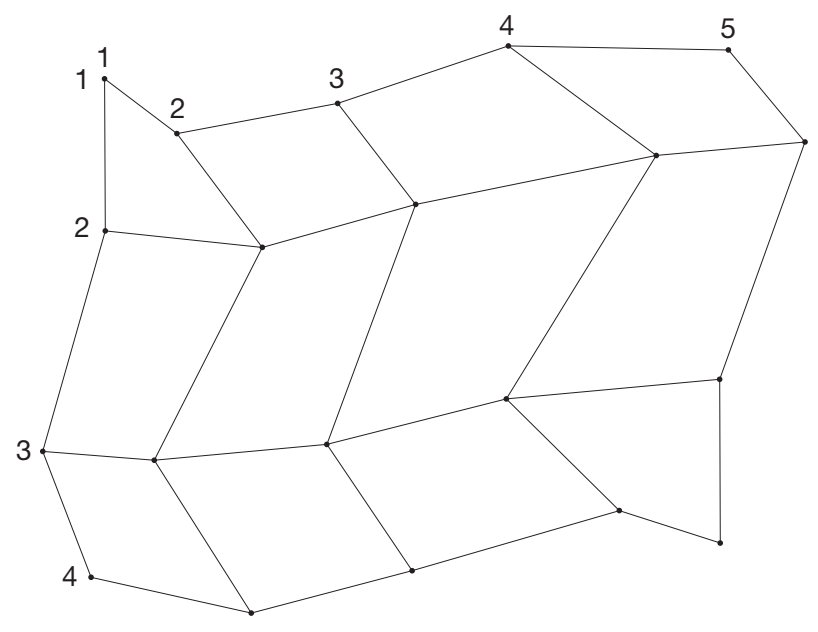

Fig. 3. Sammon mapping of SOM shown in Fig. 2
Table 1. Frequency of days (\%) that map to each self-organizing map (SOM) node shown in Fig. 2. Total no. of days: 6710

\begin{tabular}{|lccccc|}
\hline Node & 1 & 2 & 3 & 4 & 5 \\
\hline 1 & 8.69 & 4.55 & 4.81 & 5.22 & 4.11 \\
2 & 4.55 & 5.69 & 4.81 & 3.77 & 6.30 \\
3 & 5.41 & 3.90 & 4.53 & 4.84 & 3.90 \\
4 & 3.90 & 4.71 & 4.38 & 4.53 & 7.38 \\
\hline
\end{tabular}

left portion of the SOM, nodes 1,$1 ; 1,2 ; 2,1$ ) and about $40 \%$ of the days map to patterns with an eastward shift of the Aleutian Low (located along the right portion of the SOM, the rightmost 2 columns). Patterns which are largely dominated by high pressure through the entire area (lower left part of the SOM, nodes 1,$3 ; 1,4 ; 2,3$; 2,4 ) account for approximately $18 \%$ of the days. Patterns with lower pressure near and north of Barrow (nodes 2,$2 ; 3,1 ; 3,2$ ) account for $15 \%$ of the days. This demonstrates the relatively low frequency of cyclones passing to the north of Barrow. The remainder of the days map to transitional states between these dominant patterns.

To relate local weather conditions to these largescale patterns, daily surface observations at Barrow were mapped to the SOM. Fig. 4 shows the daily temperature anomalies at Barrow, averaged for each node over all days that map to the node in question. These were calculated by finding the temperature anomaly for each day relative to the entire data set being considered, then averaging these anomalies over all days with SLP patterns that correspond to each node. In general, negative temperature anomalies are located in the lower and right portion of the SOM (bottom row and nodes 4,$1 ; 2,3 ; 2,4 ; 3,3$ to 3,5 ) with positive temperature anomalies mapping to the upper left (nodes 1,1 to 3,$1 ; 1,2 ; 2,2 ; 1,3 ; 2,3$ ) and upper right (nodes 5,1 ; $5,2)$ portions of the SOM. These anomalies are dynamically consistent: the SLP patterns associated with the

Temperature anomaly $\left({ }^{\circ} \mathrm{C}\right)$

\begin{tabular}{|c|c|c|c|c|c|c|}
\hline \multirow{5}{*}{$\begin{array}{l}>1.5 \\
1.0 \text { to } 1.49 \\
0.5 \text { to } 0.99 \\
0.0 \text { to } 0.49 \\
-0.50 \text { to }-0.01 \\
-1.00 \text { to }-0.51 \\
-1.50 \text { to }-1.01 \\
-2.00 \text { to }-1.51 \\
<-2.00\end{array}$} & & 1 & 2 & 3 & 4 & 5 \\
\hline & 1 & 1.80 & 1.42 & 0.66 & -0.31 & 0.07 \\
\hline & 2 & 1.75 & 0.66 & -0.97 & -1.05 & 0.33 \\
\hline & 3 & 1.47 & 0.81 & -0.84 & -1.41 & -1.16 \\
\hline & 4 & -0.47 & -0.39 & -2.06 & -1.03 & -1.05 \\
\hline
\end{tabular}

Fig. 4. Average daily temperature anomalies $\left({ }^{\circ} \mathrm{C}\right)$ at Barrow, averaged for each SOM node over all days that map to the node in question during August-November (1950-2004) 
positive anomalies place Barrow to the east of low pressure systems, in an area of southerly flow. Conversely, the SLP patterns associated with the negative anomalies either place Barrow under the influence of a high pressure system or to the east of the high, with associated northerly to north-easterly flow. Negative temperature anomalies are also associated with an eastward shift of the Aleutian Low, which again places Barrow in an area of northerly to easterly flow.

While increasingly high temperatures are of some concern to the local community, adaptations have largely been made to these conditions. Of greater concern to the people of Barrow is the incidence of high winds. Fig. 5 shows the average wind speed anomalies mapped to each node. These numbers were calculated in the same manner as the temperature anomalies. Positive wind speed anomalies are associated with patterns in the lower right portion of the map (nodes 5, 2 to $5,4 ; 4,4 ; 3,3)$ and 2 patterns along the left side of the map (nodes 1,$1 ; 1,3$ ). These patterns exhibit a strong pressure gradient between the Aleutian Low and Beaufort/Chukchi high with a strong pressure gradient over Barrow. Negative anomalies are concentrated along the top portion extending toward the bottom left of the SOM (nodes $2,1-5,1 ; 1,2-4,2 ; 3,2 ; 3,4 ; 1,4-3,4$ ). As would be expected, to the extent that broad scale pressure patterns are associated with local winds, the patterns associated with negative anomalies are those dominated by a broad high pressure system throughout the study area and a weak pressure gradient near Barrow.

To focus on the synoptic circulation patterns (nodes) that are associated with the highest daily wind speed observations, the SLP fields for days on which the average daily wind speed was in the upper 10th percentile (9.1 $\mathrm{m} \mathrm{s}^{-1}$, approximately $20 \mathrm{mph}$ ) and the upper 1st percentile (12.9 $\mathrm{m} \mathrm{s}^{-1}$, approximately $\left.29 \mathrm{mph}\right)$, respectively, were presented to the SOM algorithm to deter-

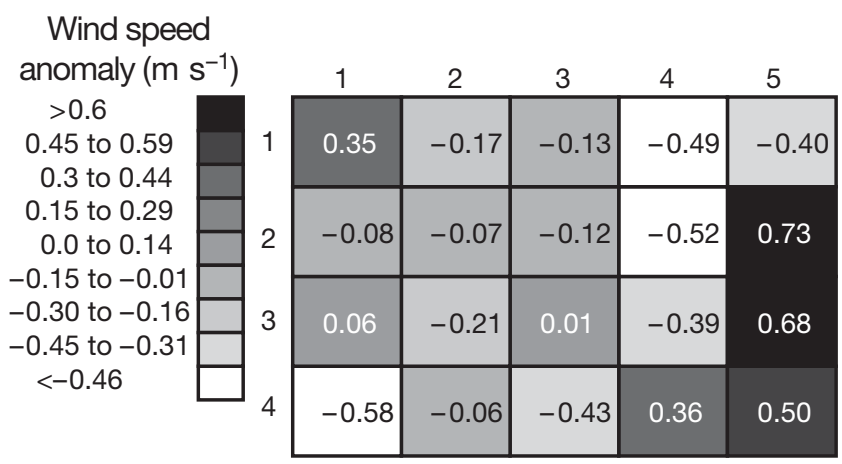

Fig. 5. Average daily wind speed anomalies $\left(\mathrm{m} \mathrm{s}^{-1}\right)$ at Barrow, averaged over all days which map to an SOM node during August-November (1950-2004)
Table 2. Percentage of high wind days that map to each SOM node shown in Fig. 2. First number: percentage of days with wind speeds $>9.1 \mathrm{~m} \mathrm{~s}^{-1}$ (ca. $20 \mathrm{mph}$ ); second number: percentage of days with wind speeds $>12.9 \mathrm{~m} \mathrm{~s}^{-1}$ (ca. $29 \mathrm{mph}$ )

\begin{tabular}{|cccccc|}
\hline Node & 1 & 2 & 3 & 4 & 5 \\
\hline 1 & $11.9 ; 14.9$ & $1.9 ; 0$ & $1.9 ; 6.0$ & $2.6 ; 3.0$ & $3.5 ; 9.0$ \\
2 & $3.2 ; 1.5$ & $3.8 ; 3.0$ & $3.2 ; 0$ & $2.6 ; 0$ & $14.2 ; 25.4$ \\
3 & $5.1 ; 0$ & $1.7 ; 4.5$ & $3.6 ; 3.0$ & $3.9 ; 0$ & $8.4 ; 4.5$ \\
4 & $2.4 ; 0$ & $4.7 ; 9.0$ & $2.3 ; 1.5$ & $6.0 ; 1.5$ & $13.1 ; 13.4$ \\
\hline
\end{tabular}

mine which nodes these circulation patterns were associated with. Table 2 shows the results of this analysis. The 2 numbers listed for each node in the table represent the percentage of days out of the total number of high wind days that mapped to the node in question for the 9.1 and $12.9 \mathrm{~m} \mathrm{~s}^{-1}$ daily wind speed thresholds, respectively. This table shows that many of the high wind days map to patterns along the right side of the SOM (especially nodes 5,2 to 5,4 ) which contain a strong pressure gradient over Barrow between the Aleutian Low and high pressure over the Beaufort and Chukchi Seas. This result confirms the reports of local residents, which suggest that in general the strongest winds are easterlies (R. Glenn, pers. comm.), but that these winds are less impact relevant than the rarer westerlies.

The most damaging storms in Barrow are generally associated with the passage of a low pressure system to the north of Barrow, creating high westerly winds at Barrow. The location of Barrow on a northwest facing shore puts it at risk of flooding and erosion due to Ekman transport forced by high westerly winds. The high wind analysis was further restricted by mapping SLP fields to the SOM for days which both fell in the high wind categories from above (9.1 and $12.9 \mathrm{~m} \mathrm{~s}^{-1}$, respectively) and reported westerly winds (wind directions between $240^{\circ}$ and $300^{\circ}$ ) (Table 3). Most days on which extreme westerlies occurred map to patterns located in the center portion of the map (especially nodes 2,2 to 2,$4 ; 3,2$ to 3,3 ), which have lower pressure near Barrow compared to the rest of the study area. Though in general these patterns do not appear to

Table 3. Percentage of westerly high wind days that map to each SOM node shown in Fig. 2. First number: percentage of days with wind speeds $>9.1 \mathrm{~m} \mathrm{~s}^{-1}$ (ca. $20 \mathrm{mph}$ ); second number: percentage of days with wind speeds $>12.9 \mathrm{~m} \mathrm{~s}^{-1}$ (ca. $29 \mathrm{mph}$ )

\begin{tabular}{|lccccc|}
\hline Node & 1 & 2 & 3 & 4 & 5 \\
\hline 1 & $2.1 ; 0$ & $3.2 ; 0$ & $5.4 ; 8.3$ & $5.4 ; 8.3$ & $1.1 ; 0$ \\
2 & $5.4 ; 8.3$ & $12.9 ; 8.3$ & $11.8 ; 0$ & $2.2 ; 0$ & $2.2 ; 0$ \\
3 & $3.2 ; 0$ & $4.3 ; 16.7$ & $12.9 ; 8.3$ & $3.2 ; 0$ & $0 ; 0$ \\
4 & $2.2 ; 0$ & $18.3 ; 033.3$ & $2.2 ; 8.3$ & $2.2 ; 0$ & $0 ; 0$ \\
\hline
\end{tabular}


have a strong pressure gradient at Barrow, they are representative of a range of patterns in which higher pressure is dominant through much of the domain, particularly the southern portion of the domain, with some patterns containing a low pressure area north of Barrow. Because many of the impact relevant cyclones passing to the north of Barrow are mesoscale in size, they are generally not well captured by the re-analysis data. Hence, their presence must be inferred from the confluence of high wind observations at Barrow and the broader scale synoptic patterns.

The fact that the conditions at Barrow were consistent with the large-scale circulation patterns demonstrates the ability to use the SOM algorithm for downscaling of both analyses and GCM scenarios, provided that adequate training for current climatic conditions is undertaken first. This also suggests that some confidence can be placed in the use of the SOM as a forecast and training tool by the local NWS office in Barrow.

\section{SYNOPTIC PATTERNS ASSOCIATED WITH EXTREME EVENTS AT BARROW}

The previous section showed how high wind days mapped to the general classification of all SLP patterns for the western Arctic, and associated temperature and wind anomalies with these general patterns. To further draw out the details of the circulation patterns associated with extreme temperature anomalies and high wind days, the SOM was trained using only days in which the daily observations at Barrow met specific thresholds for these parameters.

\subsection{Temperature}

Fig. 6 shows the SOM produced by training the SLP with days that reported a temperature anomaly $>11.95^{\circ} \mathrm{C}$, which represents the top 1 st percentile of temperature anomalies over the time period. A clear difference between Fig. 6 and Fig. 2 is the lack of patterns in Fig. 6 containing an Aleutian Low centered in the Gulf of Alaska (that is, shifted east). In the patterns that do contain an Aleutian Low, it is shifted to the west, placing Barrow in a region of southerly flow. Located in the top right portion of the map (nodes 4,1 ; 5,$1 ; 4,2 ; 5,2$ ) are patterns with a strong low located to the west and northwest of Barrow. In these patterns, the large-scale circulation places Barrow in a region of strong, southerly flow. Calculating the frequency of occurrence of each node, about half of the days map to the left portion of the map, in which high pressure is largely dominant east of Barrow. The rest of the daily SLP data map to patterns on the right side of map which exhibit differing locations of low pressure around Barrow, also placing Barrow in an area of southerly flow.

Fig. 7 shows the SOM produced by training with days that reported a temperature anomaly $<-12.10^{\circ} \mathrm{C}$, which represents the bottom 1 st percentile of temperature anomalies over the time period. Most of the patterns show a high pressure center located directly over Barrow. Patterns located in the lower left portion of the map (nodes 1,$3 ; 2,3 ; 1,4 ; 2,4$ ) place Barrow to the east of a high pressure system with associated north to northwesterly flow at Barrow.

\subsection{High wind}

The same wind categories are used here as in Section 3, that is, days in the top 10th percentile (>9.1 $\mathrm{m} \mathrm{s}^{-1}$ ) and days in the top 1st percentile $\left(>12.9 \mathrm{~m} \mathrm{~s}^{-1}\right)$. Fig. 8 shows the SOM produced by using only days where the average daily wind speed is $>9.1 \mathrm{~m} \mathrm{~s}^{-1}$. Comparing this classification to the general SLP classification (Fig. 2), the patterns show a similar layout in which the Aleutian Low dominates much of the right portion of the array (the rightmost 3 columns). In Fig. 8, however, there are more patterns which contain an Aleutian Low, which accurately represents the probability density function of the data subset. The Aleutian Lows are also deeper than in the general classification, and are coupled with a stronger high pressure area over the Beaufort and Chukchi Seas, producing a strong pressure gradient at Barrow. There are 3 patterns in the upper left portion of the map with a low to the north of Barrow (nodes 1,$1 ; 1,2 ; 2,1)$. In general, the patterns for the high wind SOM show a stronger pressure gradient near Barrow and throughout the study area, which is to be expected for high winds. Analysis of the frequency of occurrence of the synoptic patterns shown in Fig. 8 indicate that node 1,1 (with a strong low pressure center north of Barrow) and those patterns along the right side of the map with a strong pressure gradient from the Beaufort/Chukchi area to the Aleutian Islands are the most common synoptic patterns associated with high wind events.

SOM analyses of even stronger high wind days, with average daily wind speeds $>12.9 \mathrm{~m} \mathrm{~s}^{-1}$, show similar results, with a strong pressure gradient near Barrow and throughout the study area (not shown). There are 5 patterns with a strong low north of Barrow compared to just 2 for Fig. 8. This suggests that the strongest winds at Barrow are more often associated with the passage of low pressure systems through the Beaufort and Chukchi Seas, a synoptic pattern that is not very common during August through November. 

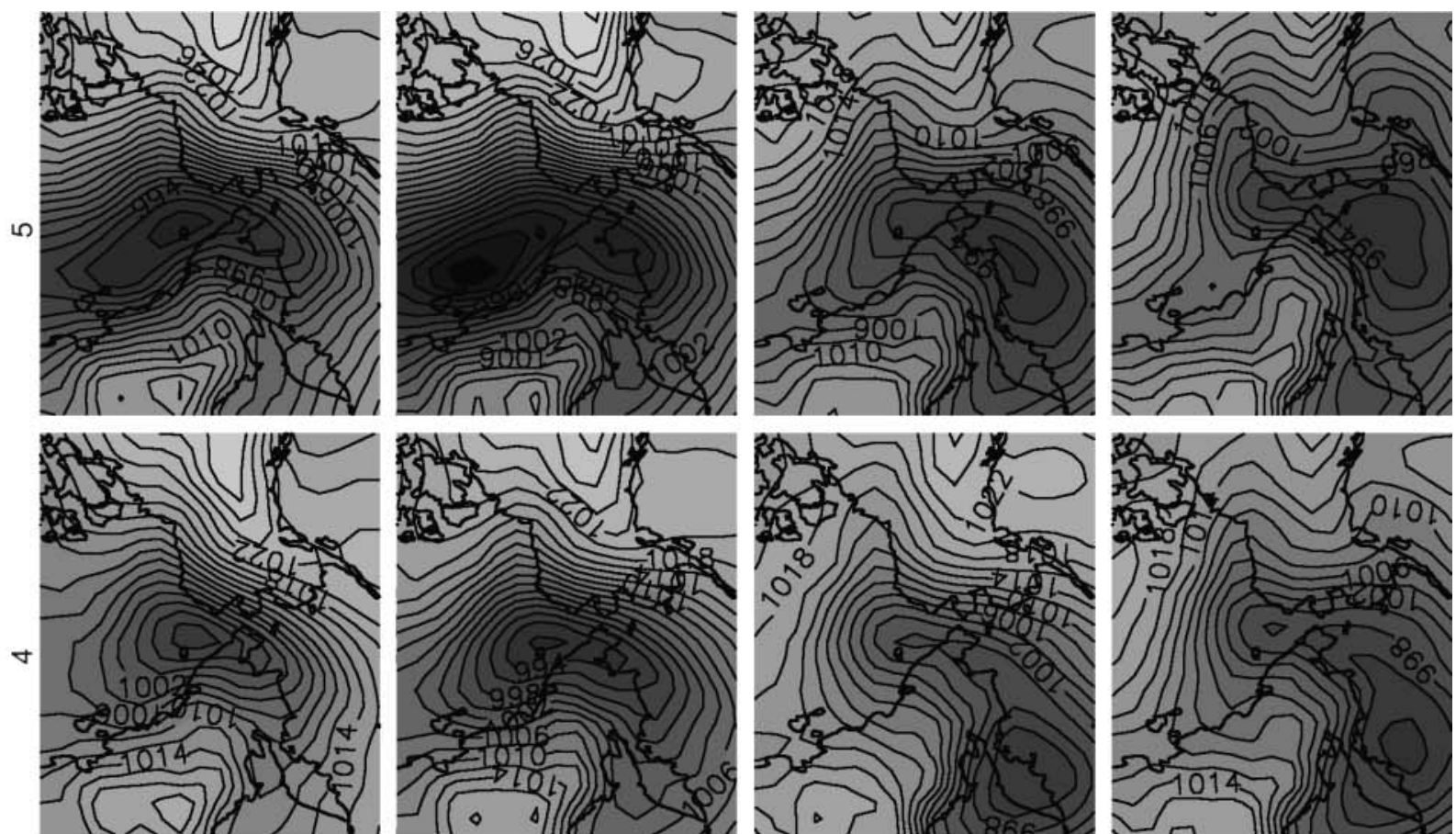

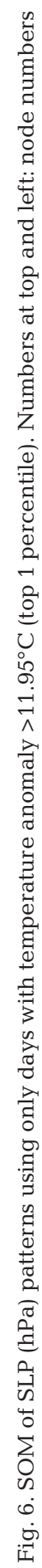
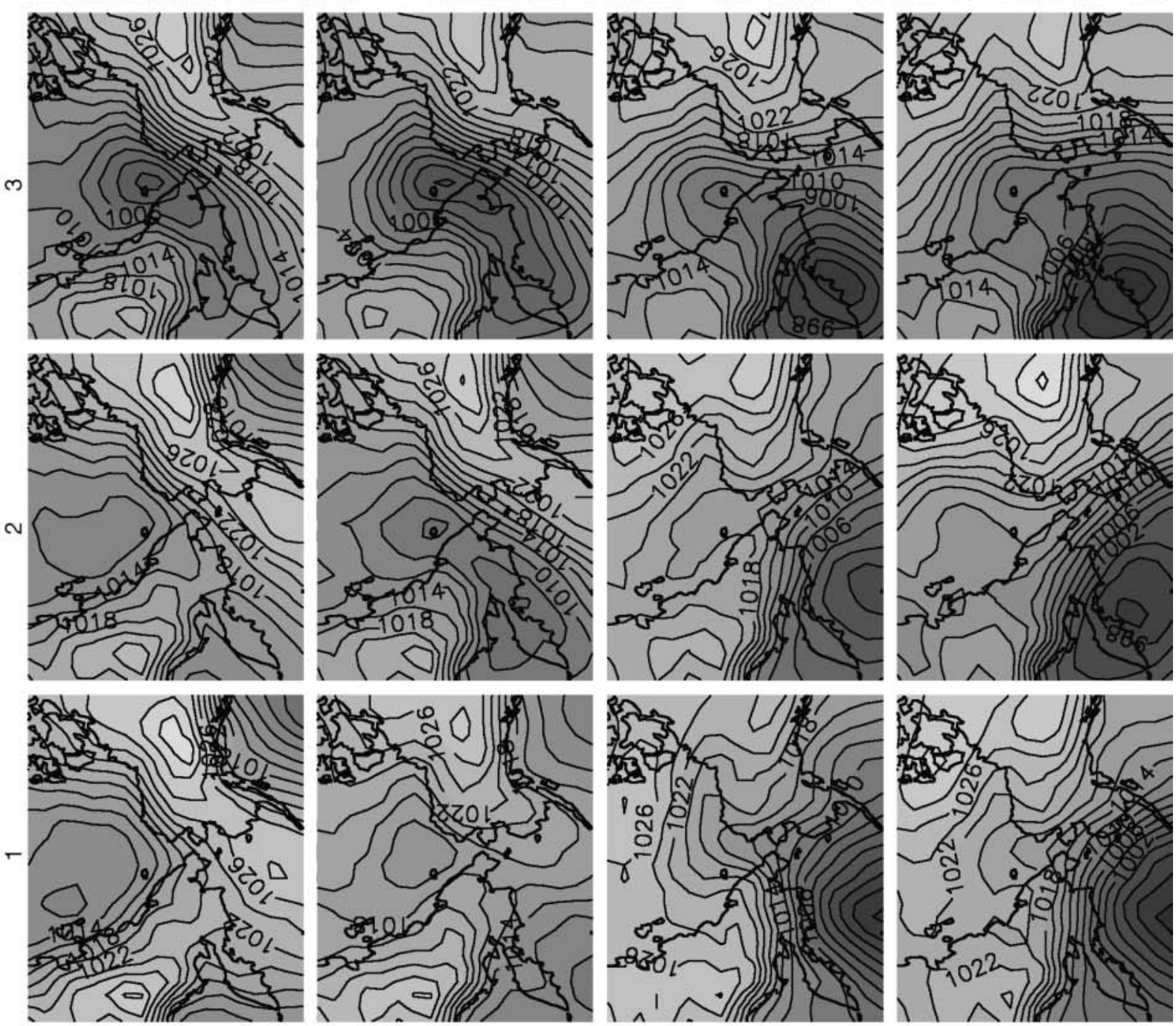

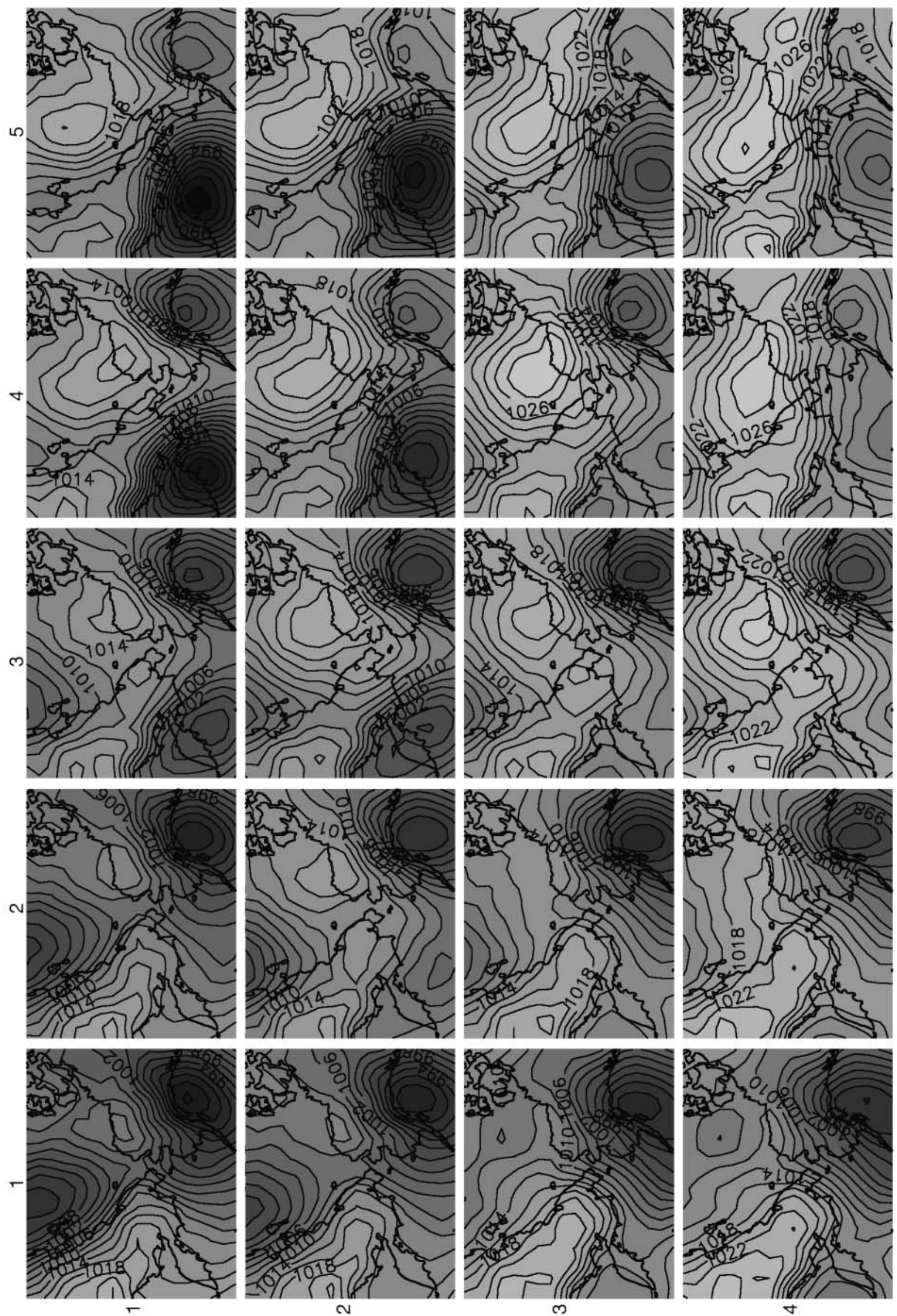

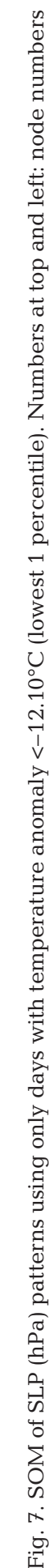



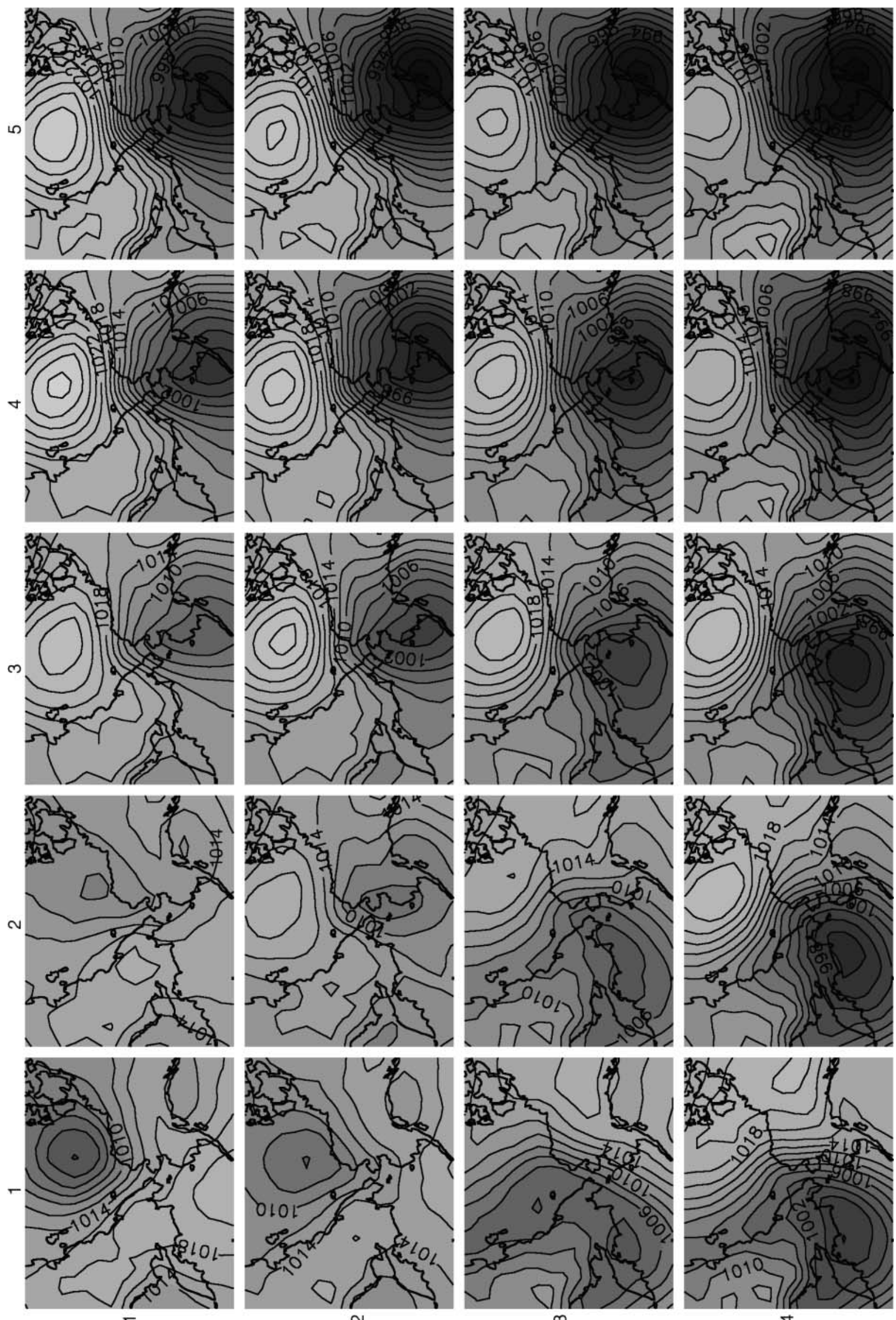

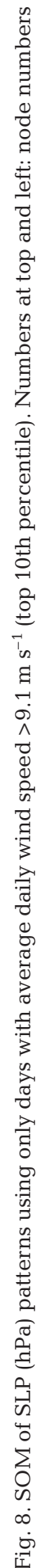


The SOM was then used to more narrowly focus on days with high westerly winds at Barrow. The same wind speed categories were used, but using only the days with westerly wind directions $\left(240^{\circ}\right.$ to $300^{\circ}$, the direction of open water from Barrow). Fig. 9 shows the SOM produced using only SLP data from days with average daily wind speeds $>9.1 \mathrm{~m} \mathrm{~s}^{-1}$ and westerly wind directions at Barrow. This SOM allows the full distribution of Beaufort/Chukchi cyclones to be characterized. Analysis of higher wind speeds (days with average daily winds speeds $>12.9 \mathrm{~m} \mathrm{~s}^{-1}$ ) and westerly winds again show the same patterns, but with stronger low pressure systems north of Barrow and stronger pressure gradients across the study area. Analysis of these synoptic situations and of previous work (Lynch et al. 2003) demonstrates that the vast majority of the lows identified in this SOM form over Siberia along the Arctic Front, migrate northward into the East Siberian Sea, and then follow an unusual eastward track rather than the more typical northward track. Most of these cyclones are synoptic scale frontal cyclones, but some of the most extreme events in Barrow have been associated with Polar-low type mesoscale developments embedded in the synoptic scale cyclonic environment. Nevertheless, this analysis suggests that an identification of the broad scale environment may be sufficient to characterize the synoptic situation conducive to an extreme westerly wind event in Barrow.

\section{CONCLUSIONS}

The SOM algorithm was used to create a synoptic climatology of the western Arctic for the months of August through November. The resulting map classifies synoptic patterns, and codifies and organizes the data so that patterns that are closely located on the map show similar qualities. The results from this classification showed the Aleutian Low to be dominant in southern Alaska with high pressure dominant in the Beaufort and Chukchi area, consistent with previous Arctic climatologies. Further refinements were then made by relating local anomalies at Barrow to each synoptic pattern in the classification. The fact that the local Barrow temperature and wind anomalies are consistent with the SLP patterns identified with the SOM algorithm indicates that the SOM is a useful tool for relating large-scale circulation features to local weather.

The highest temperature anomalies at Barrow were associated with patterns which produced strong, southerly winds. For the negative temperature anomalies, these patterns either involved a strong, broad high pressure system over the study area, or the occurrence of northerly winds. This suggests that any pat- terns of local warming (e.g. Hinzman et al. 2005) are likely to have a strong, perhaps dominant, advective component. Cassano et al. (in press) found that circulation patterns associated with high temperature anomalies over Alaska are predicted to occur less frequently in the 21st century compared to the period 1991-2000, based on an analysis of an ensemble of GCM simulations, further highlighting the importance of synoptic scale circulation on local climate.

Using the SOM algorithm to classify only those circulation patterns associated with high wind extremes at Barrow showed that these local winds are most commonly associated with a strong pressure gradient between the Aleutian Low and the Beaufort/Chukchi High. As the analysis was refined to the most extreme events, more patterns with a Beaufort or Chukchi cyclone emerged, demonstrating that the strongest winds at Barrow are often associated with the passage of cyclones through the seas to the north. Focusing on the impact relevant westerly winds, the SOMs from this analysis showed that these events were entirely due to low pressure systems to the north of Barrow.

Barrow's exposed location makes it vulnerable to storm events. During the open water season, a storm which produces a period of sustained strong winds can cause a storm surge, as well as enhanced erosion in the community and other coastal locales. For example, the most severe storm in memory and in the data records was the Beaufort cyclone on October 1963. A study of aerial photographs of the Barrow area from 1955 through the present that included 2 sets of photographs bracketing the 1963 storm showed that around $37 \%$ of the 50 year erosion was due to that one storm (P. M. Sturtevant et al. unpubl.). This demonstrates the highly episodic nature of erosion, and its strong link to extreme weather events (e.g. Harper 1978, Walker 1991). Increased population size and improved infrastructure over the past decades have increased Barrows vulnerability. It is anticipated that this climatology of potentially damaging synoptic patterns will be used by forecasters and community planners to assist in forecasting and preparing for extreme events, by characterizing the large-scale circulation associated with these events.

Through the hierarchy of analyses presented here, from broad synoptic classification for August through November to the more detailed synoptic classification for specific extreme events, the SOM method allowed local weather events to be related to broader synoptic circulation patterns as depicted in relatively coarse resolution global reanalysis data. This demonstrates the utility of the SOM methodology for assessing local climate impacts from coarse resolution circulation data. The relationships between the large-scale circulation patterns and local weather conditions at Barrow 

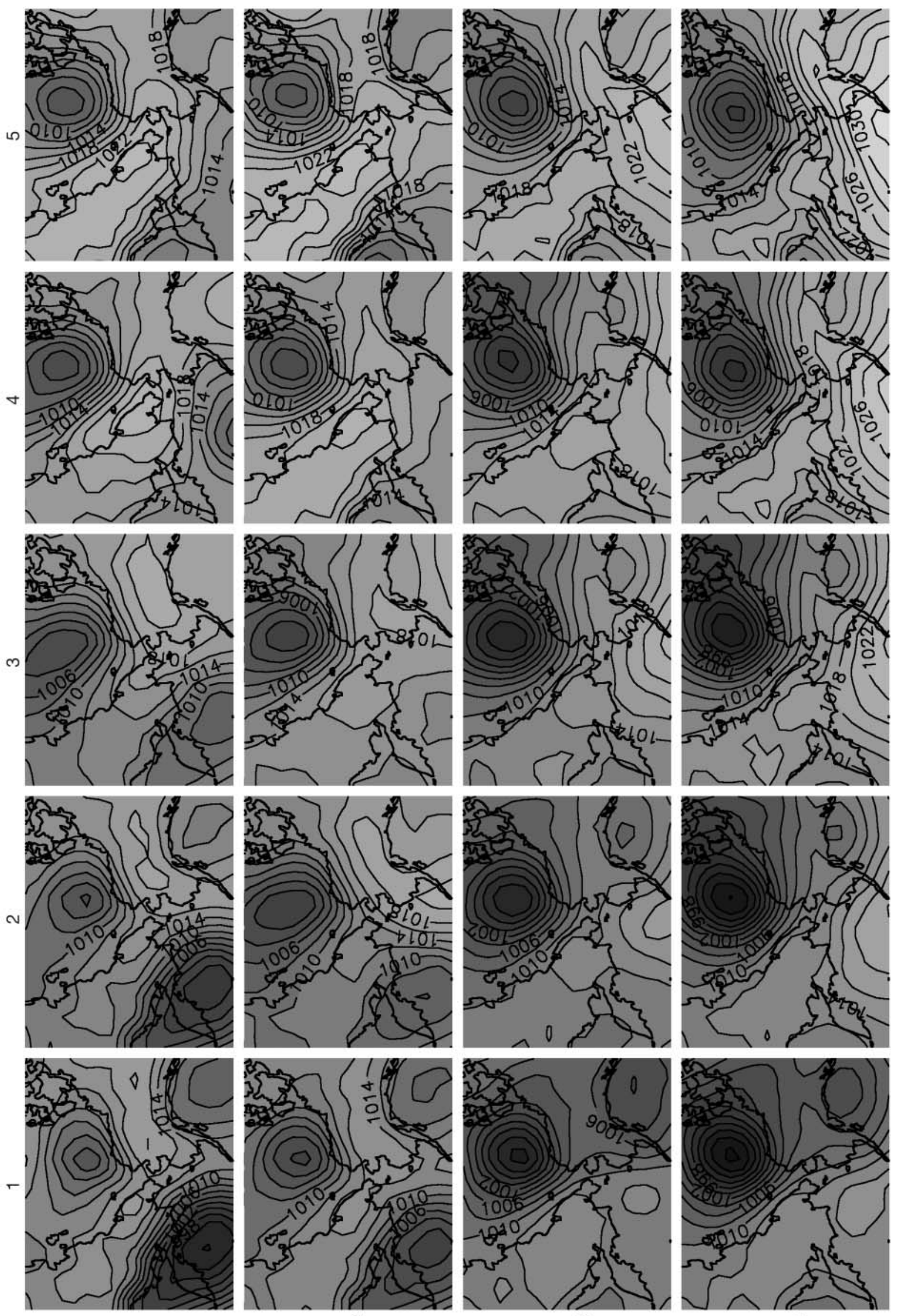
can also be applied to GCM scenarios to ascertain if large scale-circulation patterns associated with high wind events or temperature extremes in the Barrow area might be expected to increase in the future. Such an application allows the simulated field where GCMs have most skill (large scale circulation) to be used as a proxy for highly local and impact-relevant variables. The use of the SOM to find patterns in the atmospheric data and their relationships to local conditions provides a means to translate the results from GCMs into a form which is useful to local community planners.

Acknowledgements. Thanks to R. Cullather and M. Rothstein for help in data preparation, and to C. Thornbrugh for a first investigation of the SOM algorithm. L. Lestak created Fig. 1. The manuscript was improved by the comments of 3 anonymous reviewers and editor R. E. Davis. The University of Colorado SMART program and the National Center for Atmospheric Research SOARS program sponsored the work of M.R.K. and C. Thornbrugh, respectively. This research was supported by research grants NSF OPP-0100120, NSF OPP0436177 and ARC FF0348550.

\section{LITERATURE CITED}

ACIA (Arctic Climate Impact Assessment) (2004) Impacts of a warming Arctic. Cambridge University Press, New York

Ambroise C, Seze G, Badran F, Thiria S (2000) Hierarchical clustering of self-organizing maps for cloud classification. Neurocomputing 30:47-52

Barry RG, Perry AH (1973) Synoptic climatology: methods and applications. Methuen, London

Barry RG, Perry AH (2001) Synoptic climatology and its applications. In: Barry RG, Carleton AM (eds) Synoptic and dynamic climatology. Routledge, New York

Brümmer B, Thiemann S, Kirchgassner A (2000) A cyclone statistics for the Arctic based on European Centre reanalysis data. Meteorol Atmos Phys 75:233-250

Cassano JJ, Uotila P, Lynch AH (in press) Changes in synoptic weather patterns in the polar regions in the 20th and 21st centuries. Part 1. Arctic. Int J Climatol

Cavazos T (1999) Large-scale circulation anomalies conducive to extreme precipitation events and derivation of daily rainfall in northeastern Mexico and southeastern Texas. J Clim 12:1506-1523

Cavazos T (2000) Using self-organizing maps to investigate extreme climate events: an application to wintertime precipitation in the Balkans. J Clim 13:1718-1732

Crane RG, Hewitson BC (2003) Clustering and upscaling of station precipitation records to regional patterns using self-organizing maps (SOMs). Clim Res 25:95-107

Cullather RI, Lynch AH (2003) The annual cycle and interannual variability of atmospheric pressure in the vicinity of the North Pole. Int J Climatol 23:1161-1183

Esteban P, Jones PD, Martin-Vide J, Mases M (2005) Atmospheric circulation patterns related to heavy snowfall days in Andorra, Pyrenees. Int J Climatol 25:319-329

Gutiérrez JM, Cano R, Cofiño AS, Sordo C (2005) Analysis and downscaling multi-model seasonal forecasts in Peru using self-organizing maps. Tellus 57A:435-447

Harper JR (1978) Coastal erosion rates along the Chukchi Sea coast near Barrow, Alaska. Arctic 31:428-433
Hewitson BC, Crane RG (2002) Self-organizing maps: applications to synoptic climatology. Clim Res 22:13-26

Hinzman L, Bettez ND, Bolton WR, Chapin FS and 33 others (2005) Evidence and implications of recent climate change in terrestrial regions of the Arctic. Clim Change 72: 251-298

Holt T (1999) A classification of ambient climatic conditions during extreme surge events off western Europe. Int J Climatol 19:725-744

IPCC (Intergovernmental Panel on Climate Change) (2001) Climate change 2001: the scientific basis. Contribution of Working Group I to the Third Assessment Report. Cambridge University Press, Cambridge

Kalnay E, Kanamitsu M, Kistler R, Collins W and 9 others (1996) The NCEP/NCAR 40-year reanalysis project. Bull Am Meteorol Soc 77:437-471

Kaski S, Kangas J, Kohonen T (1998) Bibliography of selforganizing map (SOM) papers: 1981-1997. Neural Comput Surv 1:102-350

Keegan TJ (1958) Arctic synoptic activity in winter. J Meteorol 15:513-521

Kohonen T (2001) Self-organizing maps, 3rd edn. Springer Verlag, New York

Lamb HH (1950) Types and spells of weather around the year in the British Isles: annual trends, seasonal structure of the year, singularities. Q J R Meteorol Soc 76:393-429

LeDrew EF (1983) The dynamic climatology of the Beaufort to Laptev Sea sector of the Polar Basin for the summers of 1975 and 1976. J Climatol 3:335-359

LeDrew EF (1985) The dynamic climatology of the Beaufort to Laptev Sea sector of the Polar Basin for the winters of 1975 and 1976. J Climatol 5:253-272

Lynch AH, Cassano EN, Cassano JJ, Lestak LR (2003) Case studies of high wind events in Barrow, Alaska: climatological context and development processes. Mon Weather Rev 131:719-732

Lynch AH, Curry JA, Brunner RD, Maslanik JA (2004) Towards an integrated assessment of the impacts of extreme wind events on Barrow, Alaska. Bull Am Meteorol Soc 85:209-221

Lynch $\mathrm{AH}$, Uotila $\mathrm{P}$, Cassano JJ (in press) Changes in synoptic weather patterns in the polar regions in the 20th and 21st centuries, Part 2: Antarctic. Int J Climatol

Malmgren BA, Winter A (1999) Climate zonation in Puerto Rico based on principal components analysis and an artificial neural network. J Clim 12:977-985

McCabe GJ, Clark MP, Serreze MC (2001) Trends in northern hemisphere surface cyclone frequency and intensity. J Clim 14:2763-2768

Michaelides SC, Pattichis CS, Kleovoulou G (2001) Classification of rainfall variability by using artificial neural networks. Int J Climatol 21:1401-1414

Moritz RE (1979) Synoptic climatology of the Beaufort Sea coast of Alaska. Inst Arct Alp Res Univ Colo Occas Pap 30

NSB (North Slope Borough) (1999) Comprehensive annual financial report of the North Slope Borough, Alaska, July 1, 1998-June 30, 1999. NSB Department of Administration and Finance, Barrow, AK

Oja M, Kaski S, Kohonen T (2003) Bibliography of self-organizing map (SOM) papers: 1998-2001 addendum. Neural Comput Surv 3:1-156

Overland JE, Hiester TR (1980) Development of a synoptic climatology for the northeast Gulf of Alaska. J Appl Meteorol 19:1-14

Reed RJ, Kunkel BA (1960) The Arctic circulation in summer. J Meteorol 17:489-506

Reusch DB, Hewitson BC, Alley RB (2005) Towards ice-core- 
based synoptic reconstructions of west Antarctic climate with artificial neural networks. Int J Climatol 25:581-610 Sammon J (1969) A nonlinear mapping for data structure analysis. IEEE Trans Comput C-18:401-409

Serreze MC, Box JE, Barry RG, Walsh JE (1993) Characteristics of Arctic synoptic activity, 1952-1989. Meteorol Atmos Phys 51:147-164

Serreze MC, Walsh JE, Chapin III FS, Osterkamp T and 6 others (2000) Observational evidence of recent change in the

Editorial responsibility: Robert E. Davis,

Charlottesville, Virginia, USA northern high-latitude environment. Clim Change 46: 159-207

Solman SA, Menéndez CG (2003) Weather regimes in the South American sector and neighbouring oceans during winter. Clim Dyn 21:91-104

Walker HJ (1991) Bluff erosion at Barrow and Wainwright, Arctic Alaska. Z Geomorphol NF 81:53-61

Wigley TML (1985) Impacts of extreme events. Nature 316: 106-107

Submitted: September 12, 2005; Accepted: February 4, 2006 Proofs received from author(s): February 17, 2006 